\title{
Serum S100B Protein Levels Are Correlated with Subclinical Neurocognitive Declines after Carotid Endarterectomy
}

\author{
E. Sander Connolly Jr., M.D., Christopher J. Winfree, M.D., Anita Rampersad, B.A., Ruchey \\ Sharma, B.A., William J. Mack, M.D., J Mocco, M.D., Robert A. Solomon, M.D., George \\ Todd, M.D., Donald O. Quest, M.D., Yaakov Stern, Ph.D., and Eric J. Heyer, M.D., Ph.D. \\ Departments of Neurological Surgery (ESC, CJW, AR, RS, WJM, JM, RAS, DOQ), \\ Anesthesiology (AR, RS, EJH), Surgery (GT), and Neurology (EJH) and the Irving Center for \\ Clinical Research (ESC, YS), Columbia University, New York, New York
}

\begin{abstract}
OBJECTIVE-Carotid endarterectomy (CEA) is an effective means of stroke prevention among appropriately selected patients; however, neuropsychometric testing has revealed subtle cognitive injuries in the early postoperative period. The purpose of this study was to establish whether serum levels of two biochemical markers of cerebral injury were correlated with postoperative declines in neuropsychometric test performance after CEA.
\end{abstract}

METHODS—Fifty-five consecutive patients underwent a battery of neuropsychometric tests 24 hours before and 24 hours after elective CEA. Two patients were excluded because of postoperative strokes. The pre- and postoperative serum levels of S100B protein and neuronspecific enolase for injured patients, defined as those who exhibited significant declines in neuropsychometric test performance $(n=12)$, were compared with the levels for uninjured patients $(\mathrm{n}=41)$.

RESULTS-There were no significant differences in the baseline S100B levels for the two groups. Injured patients exhibited significantly higher S100B levels, compared with uninjured patients, at 24, 48, and 72 hours after surgery $(P<0.05)$. There were no significant differences in neuron-specific enolase levels for injured and uninjured patients at any time point.

CONCLUSION-These data suggest that subtle cerebral injuries after CEA, even in the absence of overt strokes, are associated with significant increases in serum S100B but not neuron-specific enolase levels. Analyses of earlier time points in future studies of subtle cognitive injuries and biochemical markers of cerebral injury after CEA may be revealing.

\section{Keywords}

Carotid endarterectomy; Cerebral ischemia; Neuron-specific enolase; Neuropsychological tests; S100B

Carotid endarterectomy (CEA) is an effective means to prevent stroke among patients at high risk. Although the risk of major stroke after CEA is relatively low, the incidence of subtle cognitive injuries, as revealed by neuropsychometric tests (NPMTs), is quite high $(4,6,11)$. NPMTs are sensitive measures of subtle neurological dysfunctions that are not revealed in routine neurological examinations. We recently demonstrated that as many as

Reprint requests: E. Sander Connolly, Jr., M.D., Department of Neurological Surgery, The Neurological Institute, Columbia University College of Physicians and Surgeons, 710 West 168th Street, Room 402, New York, NY 10032. Email: esc5@columbia.edu. 
$80 \%$ of patients exhibited declines in performance on at least one NPMT in the early postoperative period after CEA (11), and approximately $25 \%$ demonstrated significant declines, in comparison with a surgical control group (EJ Heyer, R Sharma, CJ Winfree, WJ Mack, RA Solomon, GJ Todd, PA McCormick, JG McMurtry, CJ Riedell, DO Quest, Y Stern, RM Lazar, EC Connolly, submitted for publication).

A variety of biochemical markers of severe neurological injury have been described. Neuron-specific enolase (NSE) is a glycolytic enzyme found in neurons and neuroendocrine cells (19). The calcium-binding protein S100B is an important participant in neuronal and glial cell-cell communication and intracellular signal transduction and exhibits its highest levels of expression in the nervous system (33). These molecules have been demonstrated to be markers of cerebral injury in animal models of stroke $(1,9)$ and among human stroke patients $(3,5,21,23,27)$.

Among patients with cerebral infarctions, high S100B levels were correlated with mildly poorer performance on NPMTs, but these results did not reach significance (32). Another study demonstrated no correlation between increased NSE and S100B levels and a decline in performance on NPMTs after CEA (25). In that study, however, the authors pointed out that the results were based on only two patients who sustained declines in NPMT performance; therefore, the study might have been underpowered. We explored whether NSE and S100B levels were correlated with declines in NPMT performance in a larger population of patients who had sustained significant, although subtle, cognitive injuries after CEA.

\section{PATIENTS AND METHODS}

\section{Subjects}

Fifty-five consecutive patients undergoing elective CEA were recruited to participate in this institutional review board-approved study, but two were excluded because of postoperative strokes. After written informed consent was obtained, patients were assessed with a battery of NPMTs at two time points, i.e., before surgery $(\mathrm{n}=53)$ and 24 hours after surgery $(\mathrm{n}=$ 53). All examinations were performed at least 3 hours after administration of any analgesic or sedative medication. All patients who experienced strokes postoperatively were excluded from the analysis. Venous blood samples $(10 \mathrm{ml})$ were obtained within 24 hours before surgery (baseline), just before internal carotid artery clamping (pre-clamp), and at 24,48 , and 72 hours after surgery. After collection, the samples were centrifuged and the serum was frozen at $-80^{\circ} \mathrm{C}$ until analysis. NSE and S100B levels were determined by using commercially available, monoclonal, two-site, sandwich immunoluminometric assay kits (LIA-mat Sangtec 100 and LIA-mat NSE; AB Sangtec Medical, Bromma, Sweden). The detection limit for NSE was $1.0 \mu \mathrm{g} / \mathrm{L}$. All control samples were within 2 standard deviations of the assigned value. In the absence of gross hemolysis, this assay exhibits no interference with erythrocyte enolase. The sensitivity of the S100B method was less than $0.02 \mu \mathrm{g} / \mathrm{L}$. All control samples were within 0.5 standard deviation of the reference value. S100B protein levels below the detection limit $(<0.02 \mu \mathrm{g} / \mathrm{L})$ were assumed to be zero. Group differences in NSE and S100B concentrations and changes from baseline values were analyzed by using an unpaired Student's $t$ test.

\section{Anesthesia and surgery}

All patients underwent general endotracheal anesthesia and continuous hemodynamic and temperature monitoring. General anesthesia was induced with fentanyl, midazolam, and either vecuronium or rocuronium and was maintained with isoflurane. Each patient was placed in the supine position, underwent continuous, eight-channel, electroencephalographic monitoring, and received a standard neck incision. After vessel exposure but before 
occlusion, heparin (5000-6000 units) was administered intravenously. No patients required shunt placement. Surgical times averaged $143 \pm 38$ minutes (mean \pm standard error) for all patients. All patients were extubated in the operating room and recovered in a postoperative care or neurological intensive care unit. All patients remained in the Irving Center for Clinical Research for 72 hours, for postoperative pain scoring and neuropsycho-logical testing.

\section{Neuropsychological evaluations}

Patients were assessed with a battery of NPMTs. One research assistant (AR), who was trained to administer and score these tests under the supervision of a neuropsychologist, administered all examinations. Four scores were generated from this battery of four NPMTs, which were chosen to represent a range of cognitive domains. Halstead-Reitan Trails Part A and B tests evaluated "visual conceptual and visuomotor tracking" by timing how long the subject required to connect consecutively numbered circles with a single line (Part A) and then to connect the same number of consecutively numbered and lettered circles by alternating between the two sequences (Part B). The Controlled Oral Word Association test evaluated verbal fluency by asking patients to produce as many words beginning with a particular letter of the alphabet $(\mathrm{C}, \mathrm{F}$, or $\mathrm{L})$ as they could in 1 minute. The scores were the sums of the number of words produced for each of the three letters. The copy portion of the Rey Complex Figure test was administered to assess perceptual and visual spatial organization. Patients were asked to copy the complex figure to the best of their ability (18). A standardized scoring system (20) was used to evaluate both the presence of specific design features and the accuracy of their locations. The degree of pain was measured at the same time NPMTs were performed. Pain was measured using a standardized, 11-point, numeric pain intensity scale, with a score of 0 representing no pain and a score of 10 representing the worst possible pain (7). Patients with pain scores of more than 5 at the time of testing were eliminated from analysis, because we previously demonstrated that pain confounds NPMT performance (13).

\section{Statistical analyses}

For each NPMT, the change in performance was calculated by subtracting the baseline score from the postoperative score. A normative data set for these changes was derived from an historical control population for each NPMT. This population was used for the purposes of $z$-score calculation and was not involved in the analysis of serum S100B or NSE levels. The mean change and standard deviation for the control population were then used to calculate a $z$-score for each test, as follows: $z$-score $=\left(\right.$ change score - mean change score $\left._{\text {spine }}\right) /$ change score $_{\text {spine }}$ standard deviation. For depiction of cognitive decline, a point system was used to transform negative $z$-scores into points for each NPMT. Points were assigned as follows: $z-$ scores greater than or equal to $-0.5,0$ points; less than -0.5 to $-1.0,1$ point; less than -1.0 to $-1.5,2$ points; less than -1.5 to $-2.0,3$ points; less than -2.0 to $-2.5,4$ points; less than -2.5 to $-3.0,5$ points; less than $-3.0,6$ points. This test deficit score measured how far each CEA patient's performance deviated from the mean performance of the control group. For each patient, the total number of test deficit scores was summed to yield the total deficit score. This total deficit score represents overall performance on the NPMT battery, whereas test deficit scores represent performance on individual NPMTs. Group differences in NPMT scores were analyzed by using the Satterthwaite modification of the unpaired $t$ test, because of differences in the variance of the measurements between groups. The cutoff for significant cognitive dysfunction after CEA was defined as a total deficit score more than 2 standard deviations above the mean of the total deficit score for the control group. The control group used in this study was an historical control group defined in our previous study (12). 


\section{RESULTS}

CEA patients with cognitive dysfunction (injured, $\mathrm{n}=12$ ) exhibited significantly higher absolute S100B levels than did patients without cognitive dysfunction (uninjured, $\mathrm{n}=41$ ) in preclamp and 24-, 48-, and 72-hour postoperative measurements $(P<0.05)$ (Fig. 1A). This difference was most pronounced at the 24-hour time point. Baseline values for these two groups did not differ significantly. Patients with cognitive dysfunction exhibited significantly greater increases in S100B levels, compared with patients without cognitive dysfunction, at $24(P<0.05), 48(P<0.001)$, and $72(P<0.01)$ hours postoperatively, when changes from baseline values were calculated (Fig. 1B).

There were no significant differences in NSE levels between injured and uninjured patients at any time point, including baseline measurements (Fig. 2A). There were no significant differences in NSE levels when changes from baseline values were analyzed (Fig. 2B).

The injured and uninjured groups did not differ significantly with respect to age, education, or other demographic or intraoperative variables (Table 1). No CEA patients were excluded from analysis because of high postoperative pain levels. Two patients were excluded because they sustained postoperative strokes. Although their baseline S100B and NSE levels were comparable to those of the other patients, their postoperative levels were substantially elevated. There was no significant relationship between the level of education and NPMT outcome scores.

The test deficit scores for each NPMT for injured and un-injured patients are presented in Table 2. Injured CEA patients performed significantly worse on the Rey Complex Figure $(P$ $<0.05)$ and Trails Part B $(P<0.05)$ tests. Of uninjured patients, $17 \%$ (7 of 41 patients) exhibited significantly improved performance on the Controlled Oral Word Association test $(P<0.001), 24 \%$ (10 of 41 patients) on the Rey Complex Figure test $(P<0.05), 24 \%$ (10 of 41 patients) on the Trails Part A test $(P<0.001)$, and $20 \%$ ( 8 of 41 patients) on the Trails Part B test $(P<0.001)$. Improvement in performance was determined by an individual test $z$ score of more than +1 .

\section{DISCUSSION}

S100B protein is a brain-specific protein found in glial cells (26). After release into the bloodstream, S100B protein is metabolized by the kidney, with a half-life of approximately 2 hours (31). Because S100B has such a short half-life, the sustained elevated levels observed in the serum of stroke patients likely represent ongoing release of the marker by perishing tissue. Specifically, as the densely ischemic infarction core expands and recruits marginally viable penumbral tissues into the enlarging necrotic region, there is sustained S100B release with the death of penumbral tissues (8).

Patients with larger cerebral infarctions exhibit significantly higher serum levels of S100B, compared with patients with smaller infarctions $(10,21)$, most likely because larger infarctions result in greater glial cell death and induce increases in S100B release into the serum (8). Large infarctions, with more extensive tissue involvement, probably require more time to evolve to completion than do smaller infarctions. If so, then S100B release should be sustained for longer periods and should peak later with larger infarctions. In fact, serum S100B levels peaked between Day 3 and Day 4 after middle cerebral artery infarctions among patients with severe functional deficits (and presumably larger infarctions), whereas levels peaked on Day 2 after less severe middle cerebral artery infarctions among patients with only moderate functional deficits (3). This phenomenon was also observed among human subjects with total anterior circulation infarctions, which yielded higher and later peak serum S100B levels than did partial anterior circulation infarctions (10). 
Cardiac bypass surgery has been demonstrated to increase serum S100B levels, likely by causing subclinical cerebral tissue death $(2,17)$. Older patients, who are more susceptible to cerebral injury during bypass procedures (30), and patients with a history of aortic atherosclerosis demonstrated elevated S100B levels 5 to 48 hours after bypass surgery (15). In the same study, bypass patients who exhibited evidence of cerebral dysfunction, such as confusion or delayed awakening, exhibited higher S100B levels 15 hours after bypass surgery, with a substantial return toward baseline levels by 48 hours. In contrast, patients at low risk who experienced no cerebral complications exhibited their highest S100B levels at the termination of the cardiac bypass procedure, with a rapid return to baseline values by 15 hours. These data suggest that more extensive cerebral injuries are associated with higher serum S100B levels, with relatively late peak times. Conversely, patients with progressively less severe cerebral damage exhibit lower and progressively earlier peak serum S100B levels.

Although NPMTs have been used to reveal subtle cognitive injuries among patients who have undergone cardiac bypass procedures $(28,29)$, not all studies have confirmed the association between cognitive injuries and S100B level increases. One negative study noted significantly elevated S100B levels among patients 24 hours after bypass surgery but the levels were not correlated with declines in NPMT performance (24). It is quite possible, however, that the S100B levels peaked much earlier in that group of very mildly injured patients and any potential correlation between NPMT performance and peak S100B levels was thus overlooked. When S100B levels were measured at an earlier time point $(5 \mathrm{~h})$ after bypass surgery, a mild decline in NPMT performance was correlated with increased S100B levels (16).

We previously demonstrated that patients who underwent CEA sustained cognitive cerebral injuries, as revealed by NPMTs (11). We also demonstrated that age-matched control subjects who underwent an identical anesthetic regimen for spinal surgery demonstrated no such decline (12). The study reported here demonstrates that these subtle injuries, even in the absence of overt strokes, are associated with significant increases in serum S100B levels 24 hours after surgery. Given the subtle nature of the injuries after uncomplicated CEA and the relatively early time of peak serum S100B levels after mild cerebral injuries, it is likely that even earlier S100B sampling (e.g., 2-8 $\mathrm{h}$ after CEA) might demonstrate an even stronger correlation between S100B levels and declines in NPMT performance. Also, a recent study of CEA patients reported increased levels of serum markers of inflammation from the jugular bulb ipsilateral to carotid artery clamping (22). We anticipate better correlation between NPMT performance and S100B levels with this more sensitive sampling technique.

Injured patients exhibit significantly elevated S100B levels not only during the postoperative period but also during the preclamp period. Although the mechanism of cerebral injury among CEA patients who demonstrate a decline in NPMT performance is unknown, it is reasonable that hypoperfusion or microemboli might be responsible. These phenomena would be expected to occur not only during internal carotid artery clamping but also during artery manipulation in the initial operative dissection. We recently demonstrated, using transcranial Doppler monitoring, that cerebral blood flow may be compromised during this dissection period (14). Any injury resulting from embolic events or hypoperfusion attributable to carotid artery manipulation might be reflected in elevated serum S100B levels before carotid artery cross-clamping.

Serum NSE levels have been demonstrated to increase after cerebral infarctions in human subjects. In some studies, NSE levels were correlated with infarction volumes $(21,23,32)$ and early neurobehavioral outcomes (32). In other studies of acute human strokes, serum 
NSE levels were not correlated with infarction volumes (8) or functional outcomes $(8,21)$. A recent study reported no correlation between postoperative NSE levels and declines in NPMT performance after CEA; however, only two patients in that study exhibited significant declines in NPMT performance (25). Our data for a larger number of injured patients support the hypothesis that NSE levels after CEA are not correlated with declines in NPMT performance. Furthermore, these data suggest that NSE levels are likely too variable and insensitive an outcome measure to be useful in studies of patients who sustain only subtle cognitive injuries after CEA.

In conclusion, subtle cognitive injuries seem to occur in 20 to $25 \%$ of patients who undergo CEA. These preliminary data demonstrating a correlation between S100B level elevations and neuropsychological deficits suggest that the injuries are associated with glial cell death and therefore may be the result of either focal or global cerebral tissue ischemia. Further studies are necessary to determine 1) the actual time course of S100B level elevations associated with subclinical cognitive declines, 2) the long-term functional significance of these elevations, and 3) the precise mechanisms by which these injuries occur. Together, these studies should help improve a procedure that is already safe and efficacious.

\section{Acknowledgments}

ESC is an Irving Assistant Professor and is supported in part by grants from the American Federation for Aging Research and the National Institutes of Health (NS2038 and NS40409). EJH is supported in part by a grant from the Charles A. Dana Foundation. We are very grateful for the excellent statistical support provided by Robert R. Sciacca, Eng.Sc.D. We sincerely thank Madeleine Höckenström, Maarit Bäcklander, and Anne-Charlotte Aronsson of AB Sangtec Medical (Bromma, Sweden) for technical support and AB Sangtec Medical for performing the serum sample analyses for NSE and S100B. We also thank Dr. Henry Ginsberg and the entire staff of the Irving Center for Clinical Research for assistance and support.

\section{REFERENCES}

1. Barone FC, Clark RK, Price WJ, White RF, Feuerstein GZ, Storer BL, Ohlstein EH. Neuronspecific enolase increases in cerebral and systemic circulation following focal ischemia. Brain Res 1993;623:77-82. [PubMed: 8221097]

2. Blomquist S, Johnsson P, Luhrs C, Malmkvist G, Solem JO, Alling C, Stahl E: The appearance of S-100 protein in serum during and immediately after cardiopulmonary bypass surgery: A possible marker for cerebral injury. J Cardiothorac Vasc Anesth 1997;11:699-703. [PubMed: 9327308]

3. Büttner T, Weyers S, Postert T, Sprengelmeyer R, Kuhn W. S-100 protein: Serum marker of focal brain damage after ischemic territorial MCA infarction. Stroke 1997;28:1961-1965. [PubMed: 9341704]

4. Crawley F, Stygall J, Lunn S, Harrison M, Brown MM, Newman S. Comparison of microembolism detected by transcranial Doppler and neuropsychological sequelae of carotid surgery and percutaneous transluminal angioplasty. Stroke 2000;31:1329-1334. [PubMed: 10835452]

5. Cunningham RT, Watt M, Winder J, McKinstry S, Lawson JT, Johnston CF, Hawkins SA, Buchanan KD. Serum neuron-specific enolase as an indicator of stroke volume. Eur J Clin Invest 1996;26:298-303. [PubMed: 8732487]

6. Cushman L, Brinkman SD, Ganji S, Jacobs LA. Neuropsychological impairment after carotid endarterectomy correlates with intraoperative ischemia. Cortex 1984;20:403-412. [PubMed: 6488816]

7. Downie WW, Leatham PA, Rhind VM, Wright V, Branco JA, Anderson JA. Studies with pain rating scales. Ann Rheum Dis 1978;37:378-381. [PubMed: 686873]

8. Fassbender K, Schmidt R, Schreiner A, Fatar M, Mühlhauser F, Daffertshofer M, Hennerici M. Leakage of brain-originated proteins in peripheral blood: Temporal profile and diagnostic value in early ischemic stroke. J Neurol Sci 1997;148:101-105. [PubMed: 9125396] 
9. Hardemark H-G, Ericsson N, Kotwica Z, Rundstrom G, Mendel-Hartvig I, Olsson Y, Pahlman S, Persson L. S-100 protein and neuron-specific enolase in CSF after experimental traumatic or focal ischemic brain damage. J Neurosurg 1989;71:727-731. [PubMed: 2809727]

10. Herrmann M, Vos P, Wunderlich MT, deBruijn CHMM, Lamers KJB. Release of glial tissuespecific proteins after acute stroke: A comparative analysis of serum concentrations of protein S-100B and glial fibrillary acidic protein. Stroke 2000;31:2670-2677. [PubMed: 11062293]

11. Heyer EJ, Adams DC, Solomon RA, Todd GJ, Quest DO, McMahon DJ, Steneck SD, Choudhri TF, Connolly EC. Neuropsychometric changes in patients after carotid endarterectomy. Stroke 1998;29:1110-1115. [PubMed: 9626280]

12. Deleted in proof

13. Heyer EJ, Sharma R, Winfree CJ, Mocco J, McMahon DJ, McCormick PA, Quest DO, McMurtry JG, Riedel CJ, Lazar RM, Stern Y, Connolly EC. Severe pain confounds neuropsychological test performance. J Clin Exp Neuropsychol 2000;22:633-639. [PubMed: 11094398]

14. Heyer EJ, Winfree CJ, Mack WJ, Connolly ES. Transcranial Doppler monitoring during carotid endarterectomy: A technical case report. J Neurosurg Anesthesiol 2000;12:233-239. [PubMed: 10905573]

15. Jönsson H, Johnsson P, Alling C, Westaby S, Blomquist S. Significance of serum S100 release after coronary artery bypass grafting. Ann Thorac Surg 1998;65:1639-1644. [PubMed: 9647073]

16. Kilminster S, Treasure T, McMillan T, Holt DW. Neuropsychological change and S-100 protein release in 130 unselected patients undergoing cardiac surgery. Stroke 1999;30:1869-1874. [PubMed: 10471438]

17. Kumar P, Dhital K, Hossein-Nia M, Patel S, Holt D, Treasure T. S-100 protein release in a range of cardiothoracic surgical procedures. J Thorac Cardiovasc Surg 1997;113:953-954. [PubMed: 9159632]

18. Lezak, MD. Neuropsychological Assessment. ed 3. Oxford University Press; Oxford: 1995.

19. Marangos PJ. Neuron specific enolase, a clinically useful marker for neurons and neuroendocrine cells. Annu Rev Neurosci 1987;10:269-295. [PubMed: 3551759]

20. Meyers, J.; Meyers, K. Rey Complex Figure Test and Recognition Trial Professional Manual. Psychological Assessment Resources, Inc.; Odessa: 1995.

21. Missler U, Wiesmann M, Friedrich C, Kaps M. S-100 protein and neuron-specific enolase concentrations in blood as indicators of infarction volume and prognosis in acute ischemic stroke. Stroke 1997;28:1956-1960. [PubMed: 9341703]

22. Parsson HN, Lord RSA, Scott K, Zemack G. Maintaining carotid flow by shunting during carotid endarterectomy diminishes the inflammatory response mediating ischaemic brain injury. Eur $\mathrm{J}$ Vasc Endovasc Surg 2000;19:124-130. [PubMed: 10727360]

23. Persson L, Hardemark H-G, Gustafsson J, Rundstrom G, Mendel-Hartvig I, Esscher T, Pahlman S. S-100 protein and neuron-specific enolase in cerebrospinal fluid and serum: Markers of cell damage in human central nervous system. Stroke 1987;18:911-918. [PubMed: 3629651]

24. Rasmussen LS, Christiansen M, Hansen PB, Moller JT. Do blood levels of neuron-specific enolase and S-100 protein reflect cognitive dysfunction after coronary artery bypass? Acta Anesth Scand 1999;43:495-500.

25. Rasmussen LS, Christiansen M, Johnson J, Gronholdt ML, Moller JT. Subtle brain damage cannot be detected by measuring neuron-specific enolase and S-100B protein after carotid endarterectomy. J Cardiothorac Vasc Anesth 2000;14:166-170. [PubMed: 10794336]

26. Shaaban Ali M, Harmer M, Vaughan R. Serum S100 protein as a marker of cerebral damage during cardiac surgery. Br J Anaesth 2000;85:287-298. [PubMed: 10992840]

27. Sindic CJM, Chalon MP, Cambiaso CL, Laterre EC, Masson PL. Assessment of damage to the central nervous system by determination of S-100 protein in the cerebrospinal fluid. J Neurol Neurosurg Psychiatry 1982;45:1130-1135. [PubMed: 7161607]

28. Smith PL, Treasure T, Newman SP, Joseph P, Ell PJ, Schneidau A, Harrison MJ. Cerebral consequences of cardiopulmonary bypass. Lancet 1986;1:823-825. [PubMed: 2870314]

29. Treasure T, Smith PL, Newman S, Schneidau A, Joseph P, Ell P, Harrison MJ. Impairment of cerebral function following cardiac and other major surgery. Eur J Cardiothorac Surg 1989;3:216221. [PubMed: 2624784] 
30. Tuman K, McCarthy RJ, Najafi H, Ivankovich AD. Differential effects of advanced age on neurologic and cardiac risks of coronary artery operations. J Thorac Cardiovasc Surg 1992;104:1510-1517. [PubMed: 1453714]

31. Usui A, Kato K, Abe T, Murase M, Tanaka M, Takeuchi E. S- $100 \mathrm{a}_{\mathrm{o}}$ protein in blood and urine during open-heart surgery. Clin Chem 1989;35:1942-1944. [PubMed: 2776321]

32. Wunderlich MT, Ebert AD, Kratz T, Goertler M, Jost S, Herrmann M. Early neurobehavioral outcome after stroke is related to release of neurobiochemical markers of brain damage. Stroke 1999;30:1190-1195. [PubMed: 10356098]

33. Zimmer DB, Cornwall EH, Landar A, Song W. The S100 protein family: History, function, and expression. Brain Res Bull 1995;37:417-429. [PubMed: 7620916] 


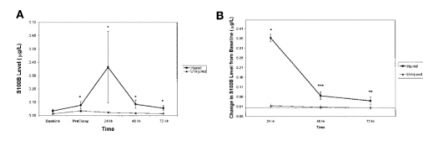

FIGURE 1.

S100B levels. A, S100B levels (mean \pm standard error) were measured preoperatively (Baseline), at the time of cross-clamping (PreClamp), and 24, 48, and 72 hours postoperatively for the injured and uninjured patient groups. There was no significant difference in baseline S100B values for the groups; however, there were significant differences at each of the remaining time points $(* P<0.05)$. $B$, when changes from baseline values were calculated, patients with cognitive dysfunction exhibited significantly greater increases in S100B levels than did patients without cognitive dysfunction at $24(* P<0.05)$, $48(* * * P<0.001)$, and $72(* * P<0.01)$ hours after surgery. 


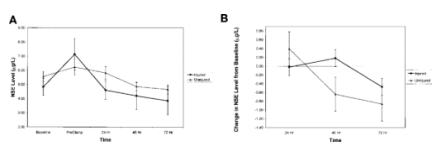

FIGURE 2.

NSE levels. A, NSE levels (mean \pm standard error) were measured preoperatively (Baseline), at the time of cross-clamping (PreClamp), and 24, 48, and 72 hours postoperatively for the injured and uninjured patient groups. There were no significant differences in the NSE values for the groups at any time point. $B$, when changes from baseline values were calculated, the injured and uninjured patient groups exhibited similar NSE values at 24, 48, and 72 hours after surgery. 


\section{TABLE 1}

Patient Demographic Characteristics ${ }^{a}$

\begin{tabular}{lcc}
\hline & Injured & Uninjured \\
\hline No. of patients & $12(23 \%)$ & $41(77 \%)$ \\
Age, (yr) & $72.7 \pm 8.7$ & $70.9 \pm 9.2$ \\
Sex (M/F) & $50 \% / 50 \%$ & $68 \% / 32 \%$ \\
Handedness (right/left) & $100 \% / 0 \%$ & $93 \% / 7 \%$ \\
Height (cm) & $169.0 \pm 12.2$ & $171.9 \pm 11.4$ \\
Weight (kg) & $78.5 \pm 23.0$ & $83.7 \pm 17.5$ \\
Education (yr) & $13.4 \pm 3.2$ & $14.2 \pm 3.3$ \\
Hypertension & $50 \%$ & $56 \%$ \\
Diabetes mellitus & $17 \%$ & $24 \%$ \\
Previous stroke or TIA & $42 \%$ & $32 \%$ \\
Previous MI & $17 \%$ & $29 \%$ \\
Previous contralateral CEA & $25 \%$ & $10 \%$ \\
Duration of surgery (min) & $155 \pm 41.2$ & $139 \pm 37.2$ \\
Fentanyl ( $\mu$ g/kg) & $1.7 \pm 0.9$ & $1.8 \pm 0.8$ \\
Midazolam (mg/kg) & $0.03 \pm 0.02$ & $0.03 \pm 0.01$ \\
Side of operation (right/left) & $42 \% / 58 \%$ & $54 \% / 46 \%$ \\
\hline$a$
\end{tabular}

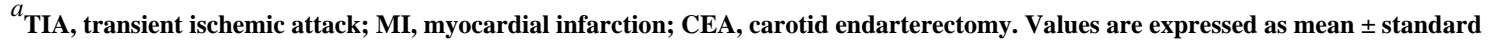
deviation or as a percentage of patients. 


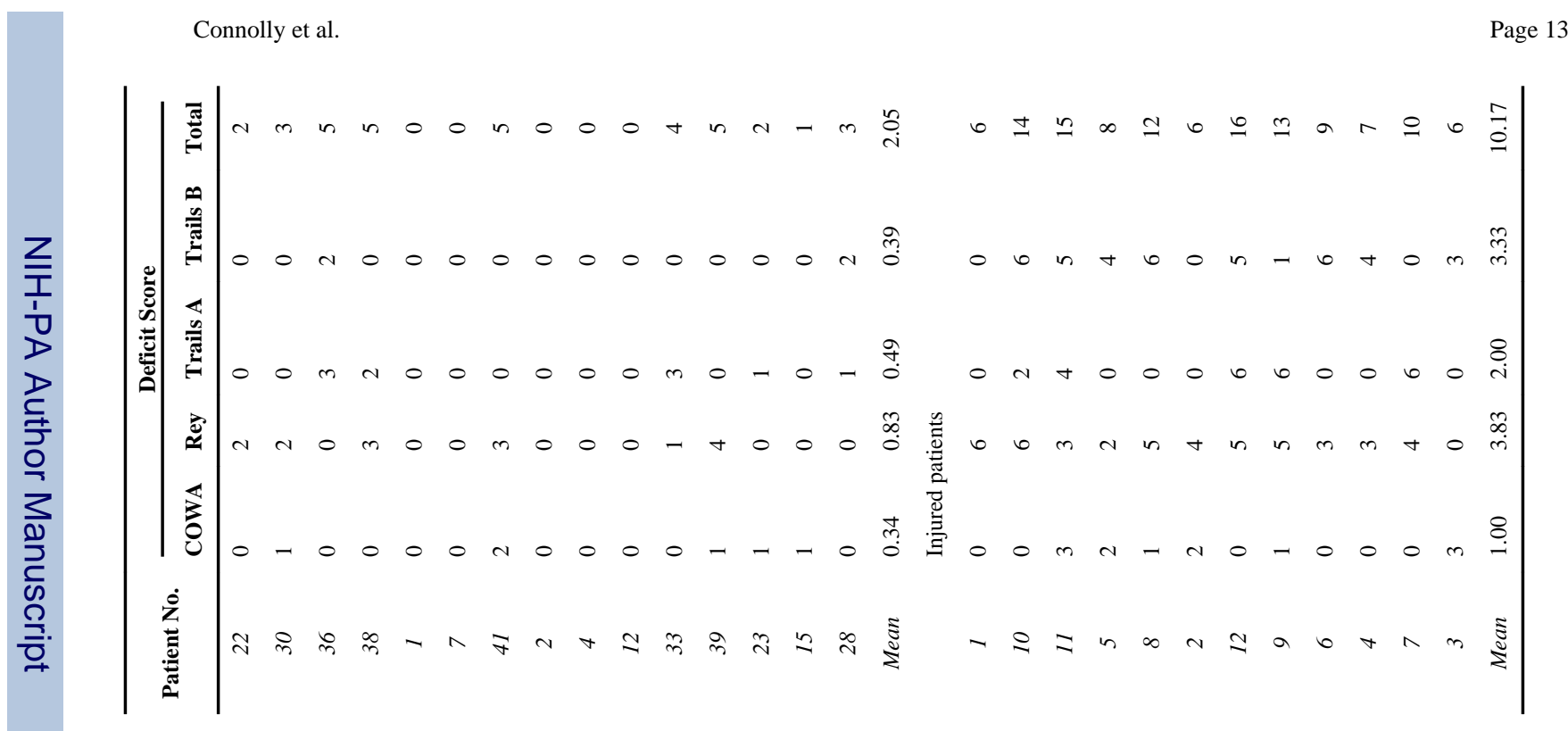


